[CONTRIBUTION FRoM THE Kent Chemical, LABóratory OF THE UNIVERSITY OF CHICAGO.]

\title{
ON THE OXYGEN ETHERS OF UREAS.
}

\author{
BY W. M, BRUCE. \\ Received February 6, 1904 .
}

THE investigations on the oxygen ethers of the ureas as carried on in this laboratory by F, B. Dains ${ }^{1}$ and R. H. McKee, ${ }^{2}$ under the direction of Professor Stieglitz, ${ }^{3}$ have been continued by me at the latter's suggestion, with the object of studying the isourea ethers from points of view which it was impossible to include in the work done by Dains and McKee.

A more detailed study was first made of the chemical nature of the acylisoureas. Stieglitz and $\mathrm{McKee}^{4}$ found that by the action of acylchlorides on monosubstituted isoureas, two series of isoureas may be obtained, the symmetric acylisourea ethers,

$$
\mathrm{RCO} \cdot \mathrm{RHC}(\mathrm{OR}): \mathrm{NR}^{\prime \prime}
$$

and the asymmetric ethers,

$$
\mathrm{RCO} . \mathrm{NR}^{\prime \prime} \mathrm{C}\left(\mathrm{OR}^{\prime}\right): \mathrm{NH} \text { (II). }
$$

These ethers are very sensitive to hydrogen chloride, which in aqueous solutions at low temperatures converts them into acylureas, with an evolution of alkyl chloride, $\mathrm{R}^{\prime} \mathrm{Cl} .{ }^{\circ}$ We have been able to show that the loss of alkyl chloride is always preceded by the formation of hydrochlorides, which were isolated and analyzed and found to be very unstable. In some cases the salts lose methyl or ethyl chloride spontaneously at ordinary temperatures. The basic character of the acylisoureas was also confirmed by the preparation of a number of chlorplatinates.

The acylisourea ethers of the first series (I) also have acid properties: McKee had observed that methyl benzoylphenylisourea is soluble in alkalies as well as in acids, but had not undertaken the isolation of any of these salts. We have been able to prepare silver and sodium salts of several derivatives of this series, thus establishing the fact of their dual or amphoteric character as bases and acids. On the other hand, we found that

1 This Journal, 21,136 (1899).

2 Am. Chem. J., 26, 209 (1901).

3 Ibid., a1, I0I (I899); Ber, d. chem. Ges., 32, I494 (1899); 33, 807 and I517 (1900).

4 Loc. cit.

b Stieglitz, McKee : Loc. cit; Wheeler and Johnson: Am. Chem. J., 24, 216 (1900). 
acylisoureas of the second series (II) have no acid properties. McKee's observation that they were soluble in alkalies was confirmed, but it could be readily proved that in dissolving they are saponified to the acids and the free isoureas, the latter of which, as will be shown below, again have the property of forming salts with both acids and bases.

Acylisoureas of the first series can also be easily obtained by the action of ammonia or amines on acylimido monothiocarbonic ethers, by the method of Miquel, ${ }^{1}$ as improved by Loessner, ${ }^{2}$ Dixon, ${ }^{3}$ and especially by Wheeler and Johnson. ${ }^{4}$ The formation of metal salts of these symmetric acylisoureas and the ready saponification of the asymmetric acyl derivatives under the influence of alkalies made it appear possible to accomplish the saponification also of the symmetric acylisoureas under conditions which would permit the isolation of the free isourea ethers and thus make Dixon's method available for the preparation of the isourea ethers themselves. Such a method would be desirable as the practical variation of the nature of the alcohol radical, $R^{\prime}$ (see I) is very limited in our present methods for preparing isoureas and nearly unlimited in Dixon's method of preparing the acyl derivatives. But all attempts to saponify the symmetric acylisoureas without completely decomposing the isourea radical were unsuccessful; very small quantities or none of the free isourea ether could be isolated.

Perhaps the most interesting observation which we have made on the acylisourea ethers is that we have been able to verify a suspicion entertained two years ago, that the isomers of asymmetric series (II) are rearranged spontaneously, but gradually into the more stable symmetric isomers $I$. The action is as follows :

$$
\mathrm{RCO} . \mathrm{NR}^{\prime \prime} \mathrm{C}\left(\mathrm{OR}^{\prime}\right): \mathrm{NH} \rightarrow\left(\mathrm{NR}^{\prime \prime}\right): \mathrm{C}\left(\mathrm{OR}^{\prime}\right) \cdot \mathrm{NH}(\mathrm{COR}) .
$$

The rearrangement is entirely analogous to other migrations of acyl groups from oxygen or nitrogen atoms to more basic neighboring amine groups, e. g., to the rearrangement of orthoaminophenylcarbonates to oxyphenylurethanes, as extensively studied

\footnotetext{
1 Ann. chim. phys., (5) 11, 318 (1877).

$2 J$.prakt. Chem., (2), 10, 237 (1874).

3 J. Chem. Soc. (London), 75, 380 (1899).

Loc. cit.
} 
by Stieglitz and Ransom, ${ }^{1}$ and Stieglitz and Upson. ${ }^{2}$ The rearrangement is also analogous to that of the isomeric acylthioureas, as studied by Professor H. L. Wheeler, ${ }^{3}$ and in order not to interfere with Professor Wheeler's investigations, we have made no further study of the rearrangement of our asymmetric acylisourea ethers beyond the establishment of the above fact.

In their work on the oxygen ethers of the ureas in this laboratory, Dains and McKee studied, in particular, to what extent these ethers exhibited the reactions of ethers and notably of the imido ethers to which they are closely allied. In the second part of this work attention was directed especially to a study of the character of the isoureas as amidines. Methylisourea, as its constitution shows, may be considered to be an amidoformimido ether, or methoxyformamidine. The study was especially inviting, because in one important particular the isoureas seemed to show a marked difference from other amidines of the aliphatic series, as studied by Pinner. This was in the fact that the isoureas can be readily isolated as free bases and are comparatively stable bodies, whereas Pinner's aliphatic amidines are described as very unstable bodies, hardly any or none of which can be prepared as free bases. ${ }^{4}$ The isoureas give the most important reactions of amidines. In particular they condense very readily with $\beta$-oxy acid esters to form pyrimidines according to:

$(\mathrm{RO})\left(\mathrm{NH}_{2}\right) \mathrm{C}: \mathrm{NH}+\mathrm{CH}_{3} \mathrm{C}(\mathrm{OH}): \mathrm{CHCOOR} \rightarrow$

NH.(RO)C : N.C $\left(\mathrm{CH}_{3}\right): \mathrm{CH} . \mathrm{CO}$.

They also form condensation products with oxalic ether, producing oxygen ethers of parabanic acid:

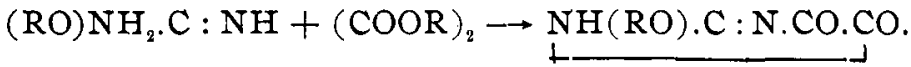

They form, therefore, a very convenient starting-point for the synthesis of the oxygen ethers of the ureides.

Whereas in these reactions both the nitrogen groups react readily-probably on account of the great tendency to form five and

\footnotetext{
1 Am. Chem. $J, 23$, I (I900).

2 Vide, a later report.

3 Am. Chem. J., 27, 270 (1902).

" Pinner, "Imidoäther," p. 90 (1892).
} 
six atomic rings-only one group is, as a general rule, ${ }^{1}$ reactive when no ring formation occurs. Thus only one amine group is attacked by benzaldehyde - a benzylidenediisourea being formed, ris:

$$
\mathrm{C}_{0} \mathrm{H}_{5} \mathrm{CH}\left[\mathrm{N}: \mathrm{C}\left(\mathrm{NH}_{2}\right) \mathrm{OCH}_{3}\right]_{2} \text {. }
$$

Acetyl chloride, chlorcarbonic ether and phenyl mustard oil also react with but one amine group.

The oxygen ethers of phenylureas were also found to form salts with metals as well as with acids--a property which is characteristic of amidines. ${ }^{2}$ In these salts the metal is held by a nitrogen atom.

It has long been a question of considerable interest to us to know just how strong the oxygen ethers of the ureas are as bases. It seemed very possible that the fundamental difference in their behavior as contrasted with that of the closely related group of the imidoethers should be due to the former's greater strength as bases and their ability to form neutral salts. ${ }^{3}$ It was also thought that it would be of interest to determine quantitatively to what extent the basic properties of the ureas are increased by converting them into their oxygen ethers. In the third part of this investigation the affinity constants of four typical isourea ethers-methyl ancl ethyl isourea and methyl and ethyl phenylisourea-were determined by conductivity methods. The results are given in the following table, together with the constants of urea $^{*}$ and several other bases, for purposes of comparison.

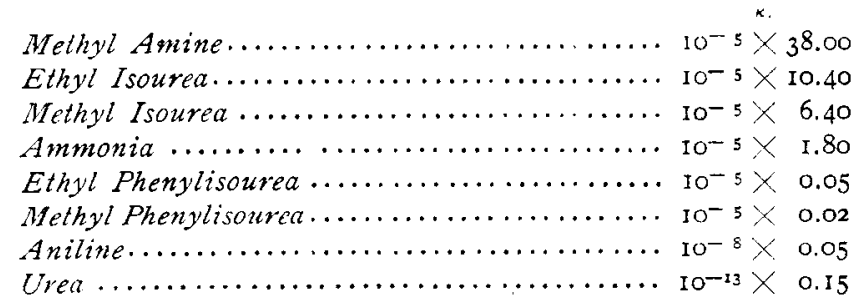

Guanidine is nearly as strong a base as the alkalies. Methyl and ethyl isourea, as mon-acid bases, are, therefore, of about the same order of strength as ammonia and the mon-alkyl amines.

\footnotetext{
t The only exception found to the rule is that two molecules of phenylisocyanate are taken up by one molecule of the isourea.

2 Bamberger: Ann. Chem. (Liebig), 273, 277 (1893).

a Stieglitz: Am. Chem. J., 21, 106.

4 See page II5.
} 
In spite of the presence of two amine nitrogen atoms they behave essentially as mon-acid bases. ${ }^{1}$ They have also exceedingly small affinity constants for a second molecule of acid, evidence of which was shown in the conductivity measurements of the hydrochlorides in extreme dilution (see Part III) and in the tendency of these bases to form solid chlorides containing at first more than one equivalent of hydrochloric acid. ${ }^{2}$

It is noteworthy that the change of urea into methyl isourea,

$$
\mathrm{NH}_{2} \mathrm{CONH}_{2} \rightarrow \mathrm{NH}_{2} \mathrm{C}\left(. \mathrm{OCH}_{3}\right) \mathrm{NH}
$$

has increased the affinity constant of the basic molecule $4 \times 10^{9}$.

\section{EXPERIMENTAL PART.}

\section{The Acylisoureas.}

The acylisoureas were obtained during this investigation by two methods: First, from acyl mustard oils by the method of Miquel, as improved by Lössner, Dixon, and Wheeler and Johnson $;^{3}$ second, the method of Stieglitz and McKee. ${ }^{3}$

The first method is very much the longer and more tedious, requiring the four successive reactions after the preparation of the mustard oils, and gives smaller yields than the second one.

By the second method the acylisoureas are very readily and simply obtained by treating the isoureas with acyl chlorides and potassium hydroxide. The isoureas themselves were very easily accessible in any quantity by the methods of Stieglitz and Dains, and Stieglitz and McKee. In some cases these have been made still more rapid and convenient by modifications by Dr. R. H. McKee of some of the experimental conditions originally used. These modifications have not yet been published by Dr. McKee, but they were kindly furnished to me by the latter while this work was in progress. The first new acylisourea prepared was the methyl ether of symmetrical $m$-nitrobenzoylphenylisourea. It was prepared in the hope that the strong negative character of the acyl radical would make it easy to saponify the body and in the expectation that it would prove to be a solid which would serve as a rapid and convenient test for the presence of methyl phenyl-

1 Vide Bredig : Ztschr. phys. Chem.. 13, 289 (1894).

2 Am. Chem. J., 26, 217 (I901).

${ }^{3}$ Loc, cit. 
isourea in oily mixtures. Only the latter expectation was fulfilled.

m-Nitrobenzoylsulphocarbimide, $m-\mathrm{NO}_{2} \mathrm{C}_{6} \mathrm{H}_{4} \mathrm{CONCS}$, was prepared from 25 grams dry lead sulphocyanate (about twice the theoretical amount) and 12.5 grams $m$-nitrobenzoyl chloride in the presence of dry benzene, according to the general method of Dixon. ${ }^{1}$ It was purified by fractional precipitation by petroleum ether and recrystallization from the same solvent. It melts at $94^{\circ}$. The analysis gave 13.58 per cent. $\mathrm{N}$; calculated, 13.49 per cent.

Methyl m-Nitrobenzoylthiocarbonate,

$$
m-\mathrm{NO}_{2} \mathrm{C}_{8} \mathrm{H}_{4} \mathrm{CONC}(\mathrm{SH}) \mathrm{OCH}_{3} \text {. }
$$

- The greater part of the benzene solution of the carbimide obtained in the last experiment was mixed with a slight excess of anhydrous methyl alcohol and the mixture was gently warmed on the water-bath and set aside for a few hours. Masses of light yellow crystals of the appearance of velvet buttons were then observed. These crystals were recrystallized from hot 80 per cent. alcohol. The substance melted at $120^{\circ}$. 3.5 grams of the pure substance were obtained. Upon evaporation the benzene solution left 4 grams of a light yellow solid, which melted at $70^{\circ}$. This was methyl $m$-nitrobenzoate.

Analysis of the crystals melting at $120^{\circ}$ gave the following figures: II.86 per cent. $\mathrm{N}$; ; calculated for $\mathrm{C}_{9} \mathrm{H}_{3} \mathrm{O}_{4} \mathrm{~N}_{2} \mathrm{~S}$, II.64 per cent.

About 3.25 grams of the carbonate were suspended in a little anhydrous methyl alcohol and the calculated amount of potassium hydroxide dissolved in the minimum amount of methyl alcohol was added. Thin, small scales of the potassium salt were precipitated. The salt, which is very soluble in water, was filtered off, washed with absolute ether and dried on a clay plate. The yield was 3 grams. Some of the salt, when heated, decomposed at about $260^{\circ}$.

Methyl Ethyl m-Nitrobenzoylimidothiocarbonate,

$$
m-\mathrm{NO}_{2} \mathrm{C}_{8} \mathrm{H}_{4} \mathrm{CONC}\left(\mathrm{SC}_{2} \mathrm{H}_{5}\right) \mathrm{OCH}_{3} \text {. }
$$

-Three grams of the above salt were suspended in a little absolute methyl alcohol and the calculated quantity ( 1.7 grams) ethyl

1 Loc. cit. 
iodide added. The needle-like crystals which formed over night were recrystallized from methyl alcohol. The melting-point was constant at $78^{\circ}$. By evaporation another crop of the crystals was obtained from the mother-liquid. The analysis gave 10.65 per cent. N.; calculated, I0.47 per cent.

$$
\begin{aligned}
& \text { Sym. O-Methyl m-Nitrobenzoylphenylisourea, } \\
& \qquad m-\mathrm{NO}_{2} \mathrm{C}_{8} \mathrm{H}_{4} \mathrm{CONC}\left(\mathrm{OCH}_{3}\right) \mathrm{NHC}_{8} \mathrm{H}_{5} .
\end{aligned}
$$

-This substance was prepared from the above compound and aniline, according to the method of Wheeler and Johnson ${ }^{1}$ for the preparation of methyl benzoylphenylisourea. Mercaptan was evolved and a dark-colored oil remained which amounted to nearly the calculated quantity for the isourea. When cooled in a freezing mixture, the oil solidified. The solid was washed with petroleum ether, dissolved in chloroform and reprecipitated by petroleum ether. The substance now had the form of needles, which melted at $124^{\circ}$.

The same compound was also prepared much more easily from methyl phenylisourea, according to Stieglitz and McKee, as follows: A mixture of I gram methyl phenylisourea in $15 \mathrm{cc}$. of alcohol-free ether and 0.4 gram potassium hydroxide in $0.5 \mathrm{cc}$. water was cooled to $o^{\circ}$ and treated with I.2 grams $m$-nitrobenzoyl chloride dissolved in a little absolute ether. A white flocculent substance separated. The ether was poured off and the residue extracted several times with more ether. The crystalline residue, insoluble in ether, was thoroughly washed with water. The yield was I gram and the melting-point $120^{\circ}$. Precipitated from a chloroform solution by petroleum ether, the substance was obtained in the form of colorless needles, which melted at $124^{\circ}$. Some of these crystals were mixed with those obtained by the method of Wheeler and Johnson, and the melting-point was unchanged. The ether extracts above obtained were now examined to see if they contained and isomeric methyl $m$-nitrobenzoylphenylisourea. The ether was evaporated and 0.3 to 0.4 gram of a somewhat mucilaginous solid was left, which, after recrystallization, proved to be identical with the substance already obtained, which melted at $\mathrm{I} 24^{\circ}$. The latter was analyzed and gave $\mathrm{I} 4.08$ per cent. $\mathrm{N}$; calculated, 14.07 per cent.

1 Loc. cit. 
Sym. m-Nitrobensoylphenylurea,

$$
m-\mathrm{NO}_{2} \mathrm{C}_{6} \mathrm{H}_{4} \mathrm{CONCONHC} \mathrm{H}_{5} \text {. }
$$

-A small amount of the isourea was decomposed by dry hydrogen chloride at $90^{\circ}$ to $I 30^{\circ}$ and gave methyl chloride and sym. $m$-nitrobenzoylphenylurea. The latter was purified by repeated extraction with boiling alcohol or by recrystallization from a large quantity of boiling alcohol. It formed very fine, colorless needles, soluble in hot water, little soluble in ether and melting at $224^{\circ}$ to a clear colorless liquid. The same substance also may be obtained from the isourea by the action of warm concentrated hydrochloric acid. The analysis gave 14.88 per cent. $\mathrm{N}$; calculated, I4.77 per cent.

Action of Potassinm Hydroxide on Sym. O-Methyl m-Nitrobenzoylphenylisourca.-Very many attempts were made to saponify the acylisourea in the hope of developing a new method of preparing isoureas. Potassium hydroxide and weaker bases $(c$. $s$. , lead hydroxide) were used in aqueous and alcoholic mixtures in the cold and at elevated temperatures. The saponification was observed to go with difficulty and to result in the almost total decomposition of any isourea that may have been first formed. Only very small quantities of the isourea were isolated. A single experiment will illustrate the process used.

Three grams methyl m-nitrobenzoylphenylisourea were boiled for one hour under a reflux condenser with 0.7 gram (I mol. - ) potassium hydroxide in Io cc. water; a little more of the alkali was gradually added, as the action seemed slow. Most of the substance finally passed into solution. The whole solution became dark red in color and smelled of aniline and ammonia. Upon cooling, a dark red gum separated out, but was not removed. Ten grams potassium hydroxide were now added and the solution extracted with ether. A dark red solid remained undissolved by the ether. This solid was dissolved in water and the solution acidified with hydrochloric acid. A brown mucilaginous precipitate was obtained. This was washed with alcohol and gave a yellow powder, which did not melt when heated to $270^{\circ}$, but blackened. The acid solution, when cooled with ice, gave another considerable precipitate, which melted sharply at $140^{\circ}$, even when mixed with $m$-nitrobenzoic acid. The ether was distilled from the ether extract and a small amount of a reddish oil remained 
which contained some colorless crystals. The oil, when tested for aniline with nitrous acid, gave a strong phenol odor and a deep red oil. The remainder of the reddish oil was taken up in petroleum ether; the colorless crystals remaining melted at $147^{\circ}$, and when mixed with phenyl urea still melted at $147^{\circ}$. The petroleum ether was distilled off and the oil which was left gave, when treated with dry hydrogen chloride, no methyl chloride. Hence no isourea was present. A very little of the oil gave a strong test for aniline with bleaching-powder. The chief products of the reaction-m-nitrobenzoic acid and aniline-showed that complete decomposition of the acylisourea had accurred.

Sym. O-Methyl Benzoylphenylisourea,

$$
\mathrm{C}_{6} \mathrm{H}_{5} \mathrm{CONC}\left(\mathrm{OCH}_{3}\right) \mathrm{NHC}_{6} \mathrm{H}_{5} \text {. }
$$

- This compound, which had been prepared both by Wheeler and Johnson, and by McKee and described by them as an oil, was obtained in the form of fine needles, which, when pure, melt at $50^{\circ}$. 5.8 grams dimethyl benzoylimidothiocarbonate were converted into the benzoylisourea ether by treatment with aniline, according to the method of Wheeler and Johnson. The resulting oil was set aside and after one day fine yellow crystals began to separate in the form of needles which, in one day more, penetrated the whole mass. As the quantity of these crystals did not increase after standing several weeks, the substance was exposed all day to the winter cold $\left(-\mathrm{JO}^{\circ}\right)$ and the whole mass solidified. The solid was purified by cooling a concentrated methyl alcohol solution of it in a freezing-mixture. The pure crystals melt at $50^{\circ}$ and evolve methyl chloride almost quantitatively when treated with dry hydrogen chloride. Some of the substance in petroleum ether solution was treated with hydrogen chloride and a precipitate was obtained which, when purified, melted at $205^{\circ}$, the melting-point of sym. benzoylphenylurea. This proves that the substance melting at $50^{\circ}$ is symmetrical methyl benzoylphenylisourea.

't he same compound was also prepared by McKee's method and obtained in crystalline form.

Action of Potassium Hydroxide on O-Methyl Benzoylphenylisourea.-Six grams of the isourea were mixed with I.4 grams (I mol.) potassium hydroxide in $25 \mathrm{cc}$. water and vigorously boiled under a reflux condenser for about a half hour. Some of 
the oil was then taken out and tested with hydrochloric acid. As the formation of benzoylphenylurea showed that a considerable quantity of the original isourea was still present, $5 \mathrm{cc}$. of alcohol and I gram more of potassium hydroxide were added and the boiling continued for another half hour. During the boiling a strong odor of ammonia was observed. All the oil finally disappeared. After the addition of $\mathrm{I}_{5}$ grams of potassium hydroxide to the cold solution a white crystalline solid separated out. This was filtered off, washed with ether and dried. The amount was r.5 grams. This solid was dissolved in water and the solution acidified with dilute hydrochloric acid. Benzoic acid was precipitated (m. p. $122^{\circ}$ ). The alkaline solution was extracted several times with ether and then acidified with hydrochloric acid; more benzoic acid was precipitated. The ether solution was dried with freshly ignited sodium sulphate and the ether distilled off. A thick, light yellow oil remained. When tested with concentrated hydrochloric acid the oil showed the presence of a small amount of the original methyl benzoylphenylisourea. Some of the residue was washed with dilute acetic acid and gave a solid, which melted at $155^{\circ}$. Some of this solid was mixed with benzanilide (m. p. $16 \mathrm{r}^{\circ}$ ) and the mixture still melted at $155^{\circ}$. The remainder of the oil was extracted with petroleum ether, which, upon evaporation, left $\mathrm{r} .4$ grams of an oil. The oil was distilled at $10-20 \mathrm{~mm}$. pressure and part of the material came over at $100^{\circ}$, but nothing more distilled, although the bath was heated to $220^{\circ}$. The distillate boiled under atmospheric pressure at $183^{\circ}$ and a few drops treated with benzoyl chloride gave benzanilide ( $\mathrm{m} . \mathrm{p}$. $16 I^{\circ}$, unchanged by synthetic benzanilide). The above residue, insoluble in petroleum ether, was dissolved in ether and I mol. (calculated for methyl phenylisourea) of potassium hydroxide in I cc. of water was added. The whole was then cooled to $0^{\circ}$ and I mol. $m$-nitrobenzoyl chloride in absolute ether was slowly added. The ether solution was then poured off and the ether was evaporated. The white, gummy mass remaining was purified by treating a chloroform solution of it with petroleum ether. A very small amount of a substance was obtained, which melted at $124^{\circ}$. The melting-point was not changed when it was mixed with $m$-nitrobenzoylphenylisourea. It follows that the substance which reacted with the $m$-nitrobenzoyl chloride was methyl phenyl- 
isourea. But it formed only a very small part of the products of the reaction. It must have been formed as follows:

$\mathrm{C}_{6} \mathrm{H}_{3} \mathrm{CONC}\left(\mathrm{OCH}_{3}\right) \mathrm{NHC}_{6} \mathrm{H}_{5}+\mathrm{KOH} \rightarrow$

$\mathrm{C}_{6} \mathrm{H}_{5} \mathrm{NHC}\left(\mathrm{OCH}_{3}\right): \mathrm{NH}+\mathrm{C}_{6} \mathrm{H}_{5} \mathrm{COOK}$.

Many other experiments, varying all possible conditions, were made on the saponification of methyl benzoylphenylisourea for the purpose of improving the yield of the phenylisourea, but nothing more than a trace was ever obtained.

It was found by Dixon that when methyl benzoylisourea was boiled with a large excess of aqueous potassium hydroxide complete saponification to benzoic acid, alcohol, carbon dioxide and ammonia occurred. My results on the action of alkalies on methyl benzoylphenylisourea also show complete saponification of the molecule, with a destruction of the urea radical.

Silver Salt of sym. Methyl Benzoylphenylisourea,

$$
\mathrm{C}_{6} \mathrm{H}_{5} \mathrm{C}(\mathrm{OAg}): \mathrm{N} \cdot \mathrm{C}\left(\mathrm{OCH}_{3}\right): \mathrm{NC}_{6} \mathrm{H}_{5} \text {. }
$$

-Silver nitrate ( $0.25 \mathrm{gram}$, a little less than I molecule) dissolved in $8 \mathrm{cc}$. of 50 per cent. methyl alcohol was slowly added to a mixture of methyl benzoylphenylisourea ( 0.4 gram dissolved in Io cc. methyl alcohol) and sodium methylate (from 0.07 gram sodium and io ce. methyl alcohol). A little silver oxide which formed was filtered off and the filtrate was treated with water; a white precipitate, very difficult to purify, was obtained. The substance was thoroughly washed with water and ether and dried on a clay plate in vacuo. A silver determination gave 30.50 per cent. Ag.; calculated for $\mathrm{C}_{15} \mathrm{H}_{18} \mathrm{O}_{2} \mathrm{~N}_{2} \mathrm{Ag}, 29.92$ per cent.

The silver salt, when treated with methyl chloride, gave chiefly methyl benzoylphenylisourea again, no alkylation of the substance being produced. The recovered benzoylphenylisourea gave methyl chloride and benzoylphenylurea (m. p. $205^{\circ}$ ) and formed a platinum salt which gave 2 I.24 per cent. platinum; calculated, 2I.24 per cent.

\section{O-Methyl Benzoylisourea Hydrochloride, $\mathrm{C}_{\mathrm{B}} \mathrm{H}_{\mathrm{B}} \mathrm{CONHC}\left(\mathrm{OCH}_{3}\right) \mathrm{NH} . \mathrm{HCl}$.}

- Methyl benzoylisourea ( $0.5 \mathrm{gram}$ ) was dissolved in absolute ether and dry hydrogen chloride passed into the solution. The precipitate was filtered off, washed with absolute ether and dried in a vacuum over concentrated sulphuric acid and solid potassium 
hydroxide. The salt now evolved methyl chloride when heated to $50^{\circ}$. The methyl benzoylisourea itself, when treated with dry hydrogen chloride without a diluent, gave off methyl chloride at ordinary temperatures. Chlorine determinations of the salt freshly prepared, and as dried for two days, gave 16.46 and $\mathrm{I} 6.06$ per cent. Cl.; calculated, 16.50 per cent.

Hence, in the course of two to three days the salt must have undergone some decomposition with the loss of methyl chloride. This conclusion is further confirmed by the fact that when II was prepared for analysis, a slight amount of the substance was found to be insoluble in water. whereas I dissolved immediately and completely.

The Sodium Salt of O-Methyl Benzoylisourea.

$$
\mathrm{C}_{6} \mathrm{H}_{5} \mathrm{C}(\mathrm{ONa}): \mathrm{N} . \mathrm{C}\left(\mathrm{OCH}_{3}\right): \mathrm{NH} \text {. }
$$

-The isourea ( 0.5 gram) was dissolved in the least possible quantity of absolute methyl alcohol and a slight excess of sodium methylate, dissolved in the minimum amount of dry methyl alcohol, was added. An oil was precipitated which, after standing for some time, solidified. In another experiment the oil solidified at once when seeded with a little of the sodium salt. The yield was quantitative. The analysis gave I 1.86 per cent. Na. : calculated, I I.50 per cent.

As in the case of the silver salt of benzoylphenylisourea methyl ether, all attempts to methylate the sodium salt led to the formation of the original substance, benzoylisourea.

Action of Acetyl Chloride on Methyl Phenylisourea.

Five grams methyl phenylisourea were dissolved in $25 \mathrm{cc}$. ether and 2 grams ( $\mathrm{mol}$. + ) potassium hydroxide in $2 \mathrm{cc}$. water were added and the mixture cooled by ice-water. The flask was then removed from the cold water and 2.7 grams (I mol.) acetyl chloride added at once and the whole well shaken for about half an hour or until all the acetyl chloride was used up. The ether solution was filtered off and the residue extracted several times with ether, the extracts being added to the first filtrate. The ether solution was dried with anhydrous sodium sulphate. filtered and evaporated in zactio. A white solid was left, mixed with a little clear, colorless oil. The oil was taken up in a little petroleum 
ether, most of the solid ( $\mathrm{X}$ ) remaining. When the petroleum tion washed with a little water, then with a very little dilute $(\mathrm{X})$ and $(\mathrm{Y})$, as will be proved presently, are the isomeric methyl acetylphenylisoureas. In the solid (X) the acetyl and phenyl groups are attached to the same nitrogen atom, and in the oil ( $\mathrm{Y}$ ) these groups are bound to different nitrogen atoms.

\section{Sym. O-Methyl Acetylphenylisourea,}

$$
\mathrm{CH}_{3} \mathrm{CONHC}\left(: \mathrm{NC}_{6} \mathrm{H}_{5}\right) \mathrm{OCH}_{3} \text {. }
$$

-The oil ( $\mathrm{Y}$ ) was dissolved in alcohol-free ether, the ether solution washed with a little water, then with a very little dilute hydrochloric acid to remove any excess of methyl phenylisourea, then three more times with a little water. It was finally thoroughly dried with freshly ignited sodium sulphate. Nearly all the ether was evaporated and the remaining ether solution decanted from a few crystals which had separated, and the ether completely evaporated. An oil was left which, when exposed all day to the winter cold, showed no tendency to solidify. The compound was identified in the following way: A small amount was dissolved in absolute ether and dry hydrogen chloride passed into the cold solution; a white precipitate, which formed at once, was filtered off and placed on a clay plate in vacuo for two days. The substance then melted at $125^{\circ}-\mathrm{I} 55^{\circ}$. Washed with alcohol and dried, the compound melted at $182^{\circ}$ to a clear colorless liquid and when mixed with synthetic sym. acetylphenylurea it still melted at $182^{\circ}$. Hence, the original oil (Y) was symmetrical O-methyl acetylphenylisourea. The latter when treated in ether solution with hydrogen chloride either reacted at once, giving the corresponding urea, or else the hydrochloride was first formed and then spontaneously decomposed when left in vacuo for two days. Experiment showed that the former reaction takes place, the methyl acetylphenylurea being formed at once from the corresponding isourea. The hydrochloride itself is, under these conditions, entirely unstable. Some of the oil $(Y)$ when treated with dry hydrogen chloride evolved methyl chloride when heated to $60^{\circ}$.

Two attempts further to identify the sym. methyl acetylphenylisourea by analysis gave low results for nitrogen, which showed that the substance was not obtained absolutely pure. Analytical 
evidence identifying it completely was obtained, however, by the preparation and analysis of its chlorplatinate.

Some of the oil ( $Y$ ) was dissolved in absolute ether and the calculated quantity of hydrochlorplatinic acid dissolved in a little absolute alcohol added. A light yellow crystalline precipitate formed immediately. This precipitate was washed several times with absolute ether and dried for half an hour over concentrated sulphuric acid and solid potassitum hydroxide. It then gave 24.73 and 24.17 per cent. Pt. ; calculated for $\mathrm{C}_{20} \mathrm{H}_{28} \mathrm{O}_{4} \mathrm{~N}_{4} \mathrm{PtCl}_{6}, 24.54$ per cent.

Asym. O-Methyl Acetylphenylisourea,

$$
\mathrm{CH}_{3} \mathrm{CO}\left(\mathrm{C}_{6} \mathrm{H}_{5}\right) \mathrm{NC}(: \mathrm{NH}) \mathrm{OCH}_{3} \text {. }
$$

-The solid $(\mathrm{X})$, recrystallized several times from boiling petroleum ether, was obtained in the form of long, beautiful, rhombic prisms which melt at $102^{\circ}$ and are very soluble in chloroform, benzene, acetone and alcohol, quite easily in ether, but somewhat less soluble in petroleum ether. The analysis gave 14.25 per cent. $\mathrm{N}$; calculated, $14.5^{8}$ per cent.

Asym. Acetylphenylurea, $\mathrm{CH}_{3} \mathrm{CONC}_{6} \mathrm{H}_{5} \mathrm{CONH}_{2}$. -The ether (X), 0.5 gram, was treated with dry hydrogen chloride. Methyl chloride, which began to form at ordinary temperature, was obtained in quantity $(35 \mathrm{cc}$.) under the influence of gentle heat, and asym. acetylphenylurea was left as a white solid in the reaction vessel. It was recrystallized twice from hot water and obtained in the form of fine needles. These melted at $\mathbf{r} 67^{\circ}$ to a turbid liquid as if on melting there had been decomposition. Mixed with sym. acetylphenylurea $\left(\mathrm{m} . \mathrm{p} .183^{\circ}\right)$ the melting-point was depressed to $154^{\circ}$.

Asym. O-Methyl Acetylphenylisourea Hydrochloride, $\mathrm{CH}_{3} \mathrm{CON}\left(\mathrm{C}_{\mathrm{B}} \mathrm{H}_{5}\right) \mathrm{C}(\mathrm{:} \mathrm{NH}) \mathrm{OCH}_{\mathrm{i}} \mathrm{HCl}$.

- The asym. acylisourea, I gram, was dissolved in absolute ether and dry hydrogen chloride passed into the cold solution. The white precipitate was washed with absolute ether and placed in vacuo over concentrated sulphuric acid and solid potassium hydroxide for forty-five minutes. A sample of the substance was then dissolved in water, only a very slight turbidity appearing, the solution neutralized with sodium bicarbonate and titrated with 
tenth-normal silver nitrate, which gave 15.60 per cent. $\mathrm{Cl}$.; calculated, I 5.49 per cent.

Asym. methyl acetylphenylisourea, when treated with dry hydrogen chloride, at once liquefied and evolved methyl chloride at the ordinary temperature.

About I.5 grams of the solid asym. acylisourea, not quite pure, was placed in a sample tube and kept for a year and a half. The tube was then found to contain an oil, near the top of which a few plate-like crystals (about 0.1 gram) adhered to the side of the tube. The substance was placed in a freezing-mixture and cooled to $\left(-10^{\circ}\right)$ for several hours, but showed no tendency to solidify. The plate-like crystals mentioned above were removed, powdered and washed with petroleum ether. The body melted at I I $2^{\circ}$, even when mixed with acetanilide. No asym. acylisourea could be obtained from the oil by treating it with petroleum ether according to the method already pursued for the separation of the two isomers. Some of the oil was now placed in a sample tube and treated with dry hydrogen chloride. Methyl chloride began to be evolved at a temperature of $60^{\circ}$. The solid residue was washed with petroleum ether and the melting-point was found to be $183^{\circ}$, which shows that the product was sym. acetylphenylurea. Hence it is evident that the asym. O-methyl acetylphenylisourea originally placed in the tube had, on being kept, passed over completely, with the exception of a small amount which had decomposed, into the more stable isomeric sym. O-methyl acetylphenylisourea. The rearrangement can be expressed as follows:

$\mathrm{CH}_{3} \mathrm{CONC}_{6} \mathrm{H}_{6} \cdot \mathrm{C}\left(\mathrm{OCH}_{3}\right): \mathrm{NH} \longrightarrow$

$\mathrm{HNC}_{6} \mathrm{H}_{5} \mathrm{C}\left(\mathrm{OCH}_{3}\right): \mathrm{NCOCH}_{3}$.

It was found that when the crystalline isomer is perfectly pure, this transformation is much slower. Some of the pure crystals when kept several months adhered to each other and the meltingpoint had fallen only $7^{\circ}-10^{\circ}$.

Action of Sodium Methylate and Silver Nitrate on Asym. Methyl Acetylphenylisourea.-A solution of sodium methylate (from 0.06 gram sodium and $3 \mathrm{cc}$. pure methyl alcohol) was added to 0.5 gram asym. methyl acetylphenylisourea (I mol.) dissolved in $2.5 \mathrm{cc}$. methyl alcohol. Silver nitrate, 0.4 gram ( $0.8 \mathrm{~mol}$.), dissolved in $5 \mathrm{cc}$. water, was gradually but rapidly added to the mix- 
ture and this thoroughly shaken and cooled under the water tap. The precipitate, which began to form at once, was at first brown, but it quickly changed to a light cream color. It was immediately filtered off, washed with a mixture of methyl alcohol and water ( $I:$ i) until the washings were no longer alkaline to sensitive litmus paper, brought on a clay plate and placed at once in a vacuum desiccator over concentrated sulphuric acid and solid potassium hydroxide. The yield appeared good. The filtrate when diluted had a strong odor of methyl acetate. As soon as the silver salt was dry, analyses were made. There was found, 4I.83, 4I.40 and 4I.83 per cent. Ag.; calculated for $\mathrm{C}_{10} \mathrm{H}_{12} \mathrm{O}_{2} \mathrm{~N}_{2} \mathrm{Ag}$, 4I.94 per cent.

From the analyses it is apparent that the silver compound obtainedi was not the salt of methyl acetylphenylisourea, but the silver salt of methyl phenylisourea itself, the acyl group having been saponified away by the treatment with sodium methylate:

$\mathrm{CH}_{3} \mathrm{CONC}_{6} \mathrm{H}_{5} \mathrm{C}(: \mathrm{NH}) \mathrm{CH}_{3}+\mathrm{NaO} \cdot \mathrm{CH}_{3}+\mathrm{AgN}()_{3} \rightarrow$ $\mathrm{CH}_{3} \mathrm{COOCH}_{3}+\mathrm{AgNC}\left(\mathrm{OCH}_{3}\right) \mathrm{NHC}_{6} \mathrm{H}_{3}+\mathrm{NaNO}_{3}$. The asym. acylphenylisoureas are therefore saponified rapidly and smoothly to isoureas, in marked contrast to their symmetrical isomers.

The same silver salt was now prepared directly from ()-methyl phenylisourea.

silver O-Methyl Phenylisourea, $\mathrm{AgNC}\left(\mathrm{OCH}_{3}\right) \mathrm{NHC}_{6} \mathrm{H}_{5}$ or $\mathrm{HNC}\left(\mathrm{OCH}_{3}\right) \mathrm{NAgC}_{6} \mathrm{H}_{5}$.- To a methyl alcohol solution of 0.5 gram methyl phenylisourea was added a solution of 0.45 gram (about $0.8 \mathrm{~mol}$.) silver nitrate in a mixture of water and methyl alcohol ( I: I) and then to the whole was added, drop by drop, with constant shaking, a concentrated sodium methylate solution prepared from 0.057 gram $(0.75 \mathrm{~mol}$.) of sodium. The pure white curdy precipitate was filtered off, thoroughly washed with cold water until the washings were no longer alkaline, then several times with very dilute acetic acid to remove any silver oxide and finally with a little methyl alcohol. The analysis gave 42.08 per cent. Ag; calculated, 4I.94 per cent.

This salt was also prepared in water solution as follows: To a saturated aqueous solution of 0.5 gram methyl phenylisourea a little less than the calculated quantity of normal sodium hydroxide was added and then the whole was treated with somewhat less than 
the theoretical amount of silver nitrate in $10 \mathrm{cc}$. of water. The salt prepared by this method had a yellow color and was much more difficult to purify than when prepared according to the method given above.

The silver salt of methyl phenylisourea, 0.5 gram, was suspended in absolute ether, the whole well cooked and a slight excess ( 3 grams) acetyl bromide added and the mixture allowed to stand in the dark for several days with frequent shaking. The ether solution was filtered off and evaporated in vacuo. 2.5 grams of an oil was left which, according to the following tests, consisted largely of sym. methyl acetylphenylisourea. Some of the oil was dissolved in absolute ether and treated with dry hydrogen chloride. A mucilaginous precipitate was filtered off and placed in vacuo over night. This precipitate, when washed with absolute alcohol and dried, melted at $183^{\circ}$. Mixed with sym. acetylphenylurea, the melting-point was unchanged.

The formation of the sym. acetyl derivative favors the following as the probable constitution of the silver salt:

$$
\mathrm{AgN}: \mathrm{C}\left(\mathrm{OCH}_{3}\right)\left(\mathrm{NHC}_{6} \mathrm{H}_{5}\right) \text {. }
$$

As a rule, the metal, in the salts of the phenyl amidines, is supposed to go to the phenylamide group. ${ }^{1}$

Silver Salt of O-Ethyl Phenylisourea, $\mathrm{HNC}_{6} \mathrm{H}_{5} \mathrm{C}\left(\mathrm{OC}_{2} \mathrm{H}_{5}\right) \mathrm{NAg}$

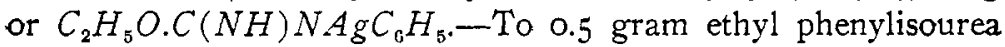
in $5 \mathrm{cc}$. absolute ethyl alcohol was added 0.5 gram ( 0.9 mol.) of silver nitrate dissolved in a mixture of water and ethyl alcohol ( I : I). The whole was then treated, slowly and with constant shaking, with an ethyl alcohol solution of sodium ethylate prepared from 0.06 gram $(0.9 \mathrm{~mol}$.) of sodium. The curdy precipitate was filtered off, washed, dried and analyzed, giving 39.88 per cent. Ag; calculated, 39.80 per cent.

Silver Salt of Sym. Methyl Acetylphenylisourea.-Sym. methyl acetylphenylisourea, 0.4 gram, was nearly all dissolved in about I 2 cc. of water and r. $8 \mathrm{cc}$. $(0.85 \mathrm{~mol}$.) normal sodium hydroxide was added and then $\mathrm{I} 6 \mathrm{cc}$. ( $0.8 \mathrm{~mol}$ ) tenth-normal silver nitrate, drop by drop. with shaking. The nearly white precipitate was filtered off, and washed with water until the washings were only slightly alkaline. An attempt was made to wash with methyl alcohol, but the

I Bamberger : Loc. cit 
first drop dissolved some of the precipitate and no more was added. The washing was completed with ether and the salt dried in the usual way. The analysis gave 35.72 per cent. Ag; calculated for $\mathrm{C}_{10} \mathrm{H}_{1: 2} \mathrm{O}_{2} \mathrm{~N}_{2 .} \mathrm{Ag}, 36.06$ per cent.

O-Methyl Acetylisonea, $\mathrm{CH}_{3} \mathrm{CONC}\left(\mathrm{OCH}_{3}\right) \mathrm{NH}_{2}$ - - Methyl isourea hydrochloride, 2 grams, and about ${ }_{5} \mathrm{cc}$. absolute ether were placed in a flask, 2 grams ( 2 mols.) potassium hydroxide in I.cc. water were added, the mixture shaken and the whole cooled to $0^{\circ}$. Two grams ( I mol.) acetic anhydride were now added and the mixture shaken for some time. The ether solution was poured off, the residue extracted again with ether and nearly the whole of the latter allowed to evaporate in the air. The extract was then placed in a vacuum desiccator for an hour or two. The substance, which was at first oily, became solid. It was purified by recrystallization from warm petroleun ether. After one recrystallization the melting-point was constant at $58.5^{\circ}$. The analysis gave 23.94 per cent. N. ; calculated, 24.19 per cent.

Silier Salt of O-Methyl Acetylisowea, $\left(\mathrm{H}_{3} \mathrm{C}(\mathrm{OAg}): \mathrm{NC}\left(\mathrm{OCH}_{3}\right): \mathrm{NH}\right.$.

- Methyl acetylisourea, I.5 grams, was dissolved in about $8 \mathrm{cc}$. absolute methyl alcohol and a concentrated methyl alcohol solution of sodium methylate ( $0.8 \mathrm{~mol}$.) was added and the whole treated with 1.3 grams silver nitrate. The white gelatinous precipitate was washed as thoroughly as possible until the washings were only very slightly alkaline. The yield was good. There was found, on analysis, 48. I 4 per cent. Ag; calculated, 48.35 per cent.

O-Methyl m-Nitrobenzoylisourea, $m-\mathrm{NO}_{2} \mathrm{C}_{6} \mathrm{H}_{4} \mathrm{CONC}\left(\mathrm{NH}_{2}\right) \mathrm{OCH}_{3}$.

- Methyl isourea hydrochloride, 3 grams, was dissolved in about $20 \mathrm{cc}$. water and 3 grams ( 2 mols.) potassium hydroxide dissolved in a little water were added and then 5.1 grams ( $\mathrm{I} \mathrm{mol}$.) $m$-nitrobenzoyl chloride and the whole thoroughly shaken. A colorless solid separated out. The yield was almost quantitative. The substance was dissolved in benzene or in chloroform and reprecipitated by petroleum ether. In this way it was obtained in the form of fine needles melting at I I $5^{\circ}$. These gave 19.00 per cent. $\mathrm{N}$. ; calculated, I 8.87 per cent.

(To be continued.) 